\title{
O Programa Nacional de Educação na ReForma Agrária (PRONERA): UMA POLITICA PÚBLICA PARA A DEMOCRATIZAÇÃO DO ESTADO NO BRASIL
}

\author{
DAISE FERREIRA DINIZ \\ Universidade Estadual do Rio de Janeiro (UERJ), Rio de Janeiro, \\ RJ, Brasil \\ Débora Franco LerRer \\ Universidade Federal Rural do Rio de Janeiro (UFRRJ), Rio de \\ Janeiro, RJ, Brasil
}

Resumo: O Programa Nacional de Educação na Reforma Agrária (PRONERA) é uma política pública do governo federal que tem por objetivo promover ações educativas nas regiões de Reforma Agrária a partir de cursos voltados para a realidade do meio rural através de uma gestão participativa e compartilhada. O presente artigo tem por finalidade dissertar sobre a trajetória do Programa Nacional de Educação na Reforma Agrária (PRONERA), demonstrando como sua operacionalização contribui para a democratização do Estado no Brasil pelo seu caráter participativo, característica fundacional do programa que deve ser constantemente reatualizada.

Palavras-chave: Políticas públicas. Participação. Movimentos sociais. Educação do campo. 
INTRODUÇÃO

Políticas públicas são processos a partir dos quais diferentes grupos sociais portadores de interesses, valores e objetivos divergentes têm a oportunidade, pelo princípio democrático da participação, de contribuírem nas tomadas de decisões coletivas, com capacidade de se converterem em resultados socialmente compartilhados (RODRIGUES, 2010, p.13). O presente artigo visa caracterizar o Programa Nacional de Educação na Reforma Agrária (PRONERA) e discorrer sobre o seu surgimento, modo de funcionamento e disputas resultantes deste seu peculiar modus operandi. Parte-se do ponto de vista de que o PRONERA é uma política pública importante para a democratização do Estado no Brasil, por se pautar por uma gestão democrática, participativa e compartilhada. Consideram-se também as implicações e os enfrentamentos gerados pelo programa, por adotar essa modalidade de gestão num país historicamente marcado por políticas públicas assistencialistas e impostas pelos desígnios dos governos que as criam. Finaliza-se o artigo refletindo, junto com as formulações de Maquiavel, sobre a importância da fundação contínua, algo que deve ser observado para a grande política a fim de garantir sua manutenção e sua renovação, a partir do que é específico de seu gesto fundador. No caso do PRONERA, seria a refundação permanente do seu modus operandi através de uma gestão democrática, compartilhada pela participação da sociedade civil organizada em movimentos sociais que lutam pela Reforma Agrária. $O$ texto encontra-se dividido em três partes. A primeira trata da história do surgimento do PRONERA, em conexão com a luta pela Reforma Agrária. A seguir, apresentam-se as áreas de abrangência dos cursos ofertados pelo programa, as organizações sociais demandantes, bem como um dos processos judiciais contra o PRONERA', oriundo de denúncias feitas ao Tribunal de Contas da União (TCU), no ano de 2008. Finalizamos com uma reflexão sobre o caráter do PRONERA, inserindo-o no rol da grande política, por inaugurar seu processo fundacional pelo instituto da participação democrática.

\section{A trajetória do Programa Nacional de Educação na Reforma Agrária} (PRONERA) NO CONTEXTO DA LUTA DOS MOVIMENTOS SOCIAIS DO CAMPO PELO DIREITO À TERRA

A história das políticas públicas no Brasil foi marcada pela ausência da participação, da proposição e da consulta às reais necessidades do público atendido ou por iniciativas exclusivas do Estado com o fito de manter o privilégio de setores sociais específicos, reforçando o seu caráter oligárquico, 
que, segundo Bobbio (1992), hoje se traduz em governos nos quais o poder supremo repousa em mãos de um restrito e fechado grupo de pessoas "ligadas entre si por vínculos de privilégios particulares", prevalecendo o interesse de poucos em detrimento das necessidades coletivas (BOBBIO, 1992, p.835). No Brasil, esse sistema oligárquico carrega em si a marca colonial de uma sociedade de base escravocrata, que confunde privilégios com direitos e naturaliza a negação de direitos a grande parcela da sociedade, fundando o que chamamos de naturalização da desigualdade social. Para Chauí (1994), o caráter oligárquico do poder no Brasil faz do Estado um espaço privado, destinado a institucionalizar os privilégios pela ausência de distinção entre o público e o privado. A não distinção entre essas duas esferas mantém as características oligárquicas do poder em políticas geralmente caracterizadas por um assistencialismo desmobilizador, que se agrava pelas construções culturais neoliberais de redução das funções do Estado e da política, associado ao "marketing narcisista da vida privada". Neste ambiente, o aparelho estatal corre mais riscos de se transformar num lócus por excelência do reforço dos privilégios em detrimento da ampliação de direitos (CHAUÍ, 1994, p.29).

Cabe esclarecer que a democracia aqui é entendida como a interação negociada entre o princípio representativo (o voto eleitoral) e o princípio participativo (organizações políticas no interior da sociedade civil e ações propositivas e deliberativas da sociedade civil organizada junto a políticas de governo), pois, como afirmou Almeida (2014):

A combinação dos aspectos característicos do sistema representativo com a possibilidade de participação social em processos decisórios [...] contribui para ampliar o espaço político e de atuação da sociedade civil na gestão pública. Cria-se uma nova institucionalidade política na qual ocorre a transferência de prerrogativas decisórias, antes somente detidas pelos governantes, para a sociedade civil, tornando-as mais democráticas, inclusivas e participativas. Tem-se assim reconhecido por meio da participação social o direito aos cidadãos de influenciarem seus governos, seja por meio de representantes legitimamente eleitos ou diretamente por intermédio da dinâmica dos arranjos institucionais participativos (ALMEIDA, 2014, p.58).

Considera-se que o princípio da representatividade democrática exorbitaria o momento do voto, passando a compor o princípio participativo, não apenas nas organizações políticas no âmbito da sociedade civil (como os movimentos sociais, sindicais etc.) como também no âmbito do Estado, por meio de ações participativas, propositivas e avaliativas das políticas públicas, configurando a interação entre os modelos representativos e participativos de democracia. 
Em abril de 1998, a Portaria no 10/1998 regulamentou o Programa Nacional de Educação na Reforma Agrária (PRONERA). Esse programa regula um recurso específico do Ministério da Educação (MEC), disponibilizado pelo Instituto de Colonização e Reforma Agrária (INCRA), que visa garantir alfabetização e instrução formal em diferentes níveis de ensino para populações assentadas. Esse programa foi uma das consequências do I Encontro Nacional dos Educadores e Educadoras da Reforma Agrária (I ENERA), ocorrido na cidade de Brasília, sediado pela Universidade de Brasília (UnB), em julho de 1997. Segundo o coordenador do Setor de Educação do Movimento dos Trabalhadores Rurais Sem Terra (MST), Edgar Kolling, foi nesse encontro que foi gestada a ideia do PRONERA, graças à sugestão do então reitor da UnB, João Claudio Todorov, que se tornou o primeiro coordenador do programa, e à grande presença de professores oriundos de diversas universidades públicas do Brasil. A própria realização do I ENERA é, na visão de Kolling, fruto de um cenário político favorável à luta pela Reforma Agrária no Brasil, reforçado pela chegada a Brasília das três colunas de sem-terra que marcharam de Goiás, São Paulo e Minas Gerais por dois meses e foram recebidos por 100 mil pessoas em Brasília, no dia 17 de abril, primeira grande mobilização de oposição ao governo Fernando Henrique Cardoso. Esse cenário favorável à luta pela Reforma Agrária era também marcado pela repercussão pública de dois massacres de sem-terra ocorridos um em Rondônia, em agosto de 1995, e, sobretudo, o de Eldorado do Carajás - PA, ocorrido no dia 17 de abril de 1996 , que tiveram alcance internacional. Esse contexto de grande visibilidade pública do descaso do Estado para com as políticas agrárias e de violência no campo favoreceu a criação do PRONERA e também do próprio Programa de Fortalecimento da Agricultura Familiar (PRONAF), criado por um decreto assinado pelo presidente $\mathrm{FHC}$ dois meses depois do massacre que resultou no assassinato de 19 sem-terra em uma rodovia do Pará pela Polícia Militar daquele estado 2 . O PRONERA nasce da grande visibilidade da luta pela terra e pela Reforma Agrária no país, protagonizada por diferentes movimentos sociais, mas com grande destaque do MST e de docentes e pesquisadores vinculados a universidades federais brasileiras. É a partir desse contexto que o PRONERA vem contribuindo para a inclusão no cenário educacional do país de uma nova modalidade de pensar a educação em suas práticas e finalidades, ou seja, ao materializar a educação do campo como política pública aplicada via gestão participativa por parte do público que delas fará uso e, assim, colocando uma nova ordem do discurso para as práticas da gestão pública no interior do Estado e ampliando as possibilidades dos espaços em que se podem figurar práticas de democracia participativa - na sociedade civil e no interior do próprio Estado. 
As políticas do PRONERA estão direcionadas a populações de áreas reformadas pelo Instituto Nacional de Colonização e Reforma Agrária (INCRA) e pelos órgãos estaduais envolvidos com política agrária, buscando atender às demandas dessas comunidades. O programa atua a partir de uma gestão participativa orientada pela interatividade com parcerias governamentais, instituições de ensino superior, organizações sindicais, movimentos sociais, bem como suas principais interessadas, as comunidades das áreas de Reforma Agrária. Ele tem por função programar políticas de educação do campo nos diferentes níveis de ensino: alfabetização, ensino fundamental, médio, educação de jovens e adultos, ensino superior e pós-graduação. Visando aprimorar o ensino para as populações rurais, o PRONERA estimula metodologias ajustadas à realidade sociocultural do campo, procurando se pautar por orientações pedagógicas que atendam às necessidades educacionais e de qualificação desses trabalhadores.

Para Félix (2015), a gestão participativa é o elemento que dá vida às atuações do PRONERA e se faz pela parceria:

A participação é um dos critérios regulamentados pelo PRONERA para a execução de projetos educacionais. Trata-se de uma participação que se faz pela parceria. Considero que a parceria nada mais é do que o "coração" do PRONERA, é esse o "coração" com os parceiros envolvidos que faz com que esse Programa ultrapasse suas fronteiras, passando a discutir dentro das universidades a participação das organizações sociais, fundamental para os projetos na perspectiva da educação do campo (FELIX, 2015, p.9).

As ações do PRONERA são motivadas pelas demandas das diferentes organizações da população do campo inscritas e beneficiárias dos programas de Reforma Agrárias fomentados pelo INCRA. Os beneficiários da Reforma Agrária (nomenclatura adotada pelo INCRA), por meio das organizações, movimentos e sindicatos, identificam a necessidade de alfabetização e qualificação em diversos níveis de sua comunidade para formar uma demanda. Essas organizações estabelecem contato com as entidades parceiras, como as universidades, institutos federais e instituições de ensino sem fins lucrativos para que juntos elaborem projetos de cursos de acordo com as demandas das populações das áreas de Reforma Agrária e a disponibilidade de profissionais e recursos pedagógicos da instituição de ensino parceira. Para esse projeto ser aprovado, ele passa pela Comissão Pedagógica Nacional (CPN), que irá julgar o mérito do projeto, propor possíveis ajustes e sua viabilidade de execução junto ao PRONERA. Nisto consiste o diferencial do PRONERA, ou seja, suas ações se pautam por necessidades reais do público usuário e participante, configurando uma horizontalidade na relação entre o Estado (PRONERA/ 
INCRA) e a sociedade civil (as organizações da população das áreas de Reforma Agrária) e instituições de ensino. Trata-se do elemento democrático e participativo contido nas ações do PRONERA, que faz do programa um contributo para a democratização do Estado no Brasil.

Considerando que um regime realmente democrático tem na participação política dos cidadãos a materialização da autonomia social, não se pode conceber uma democracia em bom funcionamento sem uma ação efetiva da sociedade como propositora de suas políticas públicas. Para Freire (2006), grande parte dos Estados contemporâneos com legitimidade democrática vem reproduzindo um tipo específico de monarca que tem transformado o funcionamento das instituições numa espécie de oligarquia ao construírem Estados gerentes da sociedade no qual: "as grandes vozes se calam, tudo passa como se, na ordem política, os princípios tivessem se tornado objeto de tão grande consenso que podem dispensar as doutrinas e os grandes debates" (FREIRE, 2006, p. 11). Para o autor, a política é oligarquizada pelos partidos e governos que obliteram o princípio fundamental da democracia: a participação política efetiva como marca da autonomia, ou seja, a capacidade de recriação constante do ambiente social pelos diferentes seres que nela figuram. É neste sentido que uma política pública que tenha com modus operandi uma gestão participativa, e que somente funciona se motivada pela participação e pelas demandas de seus parceiros, possa parecer como uma anomalia política, especialmente num país cujo regime político foi caracterizado pelo brasilianista Montero (2005) como uma democracia ancorada em um "sistema oligárquico de representação" (MONTERO, 2005, p.71), resultado da antiga tradição elitista na política brasileira e de arranjos institucionais criados durante o século XX que solaparam a participação política dos setores populares e tornaram o Estado muito mais vulnerável aos interesses das elites, favorecendo o que Montero (2005) define como "a capacidade dos interesses minoritários em impedir mudanças institucionais", uma das características mais duras e resistentes da política contemporânea brasileira (MONTERO, 2005, p.51).

Mesmo fundamentado na experiência do exercício dos direitos políticos de cidadania dos movimentos sociais em luta pela Reforma Agrária, Molina (2003) observa que o processo de construção do PRONERA, como política de governo, não se fez sem enfretamentos políticos.

1998 era um ano eleitoral para a Presidência, e como estratégia de campanha, o governo anunciou que o PRONERA alfabetizaria em um ano $200 \mathrm{mil}$ trabalhadores rurais. Depois de seis meses do anúncio da criação é que sai a Portaria no 10, criando o PRONERA em 17 de abril de 1998. [... ] Quando o 
PRONERA foi lançado advieram divergências entre o Ministério de Desenvolvimento Agrário (à época o Extraordinário de Política Fundiária) e o da Educação. A imprensa noticiou que a secretária de Ensino Fundamental, lara Prado, afirmara que "o PRONERA era uma iniciativa lastimável de educação [...]". Porém, em maio de 1998, ainda não havia sido liberado nenhum recurso para o funcionamento do Programa (MOLINA, 2003, p.56).

Outro dado levantado por Molina (2003) diz respeito ao desconforto gerado diante da participação dos movimentos sociais junto ao PRONERA:

No final de 2000 e início de 2001 procedeu-se grande mudança comandada por Francisco Orlando Muniz da Costa, presidente do INCRA: exonerou o professor João Cláudio Todorov, alegando que o MST mandava no PRONERA e o INCRA não tinha o controle das ações do Programa. Instituiu no organograma do PRONERA uma Direção Executiva e um colegiado Executivo com integrantes do INCRA. A Coordenação do Programa ficou com Ana Maria do Nascimento, à época Coordenadora dos Projetos Especiais do INCRA. O Presidente do INCRA emitiu portaria estabelecendo "ser terminantemente proibida a celebração de qualquer modalidade de convênio, no âmbito dos objetivos do PRONERA, sem a autorização oficial e expressa da coordenação Geral de Projetos Especiais [...]. Este procedimento mudou a sistemática de tramitação dos projetos, e significou na prática a perda de autonomia e a diminuição da capacidade de intervenção dos parceiros nas definições do Programa. A centralização de poder no INCRA partia a principal característica desta política pública: uma gestão participativa e colegiada, com efetiva integração dos movimentos sociais. De 2001 a início de 2003, o PRONERA ficou subordinado à Coordenação de Projetos Especiais. [Trata-se de um período caracterizado por] célebres dificuldades para manter o nível de participação dos movimentos sociais na gestão do PRONERA (MOLINA, 2003, p.58-59).

Com a ascensão de Lula à Presidência da República em 2003, o programa volta a tomar o rumo do fomento à gestão participativa. Nesse sentido, o ano de 2004 pode ser considerado um marco na consolidação do PRONERA como uma política pública operacionalizada por uma gestão participativa e compartilhada, tomando como referência o que se consolida no Manual de operações editado nesse ano. Este consiste num documento institucional que regulamenta as ações do PRONERA, dando os direcionamentos regimentais para a operacionalização das ações do programa. É através desse documento que se evidencia como se processa a participação política no interior do próprio Estado, mais especificamente no PRONERA. Ao longo de sua história, o PRONERA contou com seis reedições do Manual de operações, mas os delineamentos de seu caráter participativo e democrático foram mais efetivamente explicitados no manual editado no ano 
de 2004, período em que ele se apresenta mais claramente como uma política pública que tem por objetivo ampliar o grau de certificação e qualificação profissional da população das áreas de Reforma Agrária. Os fundamentos da execução do programa foram divididos em princípios políticos pedagógicos e operacionais. Estruturados a partir da associação entre o desenvolvimento territorial e a educação, os princípios pedagógicos abrangem quatro grandes temas, como a inclusão, participação, interação e multiplicação, conforme consta no Manual de operações de 2004:

Inclusão - a meta é a ampliação do acesso à educação entendida como um direito social de cidadania, o que requer projetos construídos na participação de todos os parceiros nos processos de elaboração, execução, acompanhamento e práticas teóricas metodológicas.

Participação- a partir da qual os projetos têm como proponentes as comunidades das áreas de Reforma Agrária e sua execução, acompanhamento e avaliação deverão ser uma ação conjunta entres os parceiros.

Interação: enfatiza a responsabilidade de diferentes agentes parceiros criando uma interação permanente entre eles pela via da educação continuada e profissionalizante;

Multiplicação: tem por objetivo não só de ampliar os números de pessoas com acesso à educação em seus diferentes níveis, como também multiplicar o número de educadoras e educadores, de técnicos e técnicas e agentes mobilizadores/as nas áreas de Reforma Agrária (BRASIL, 2004, p.18) .

Os princípios operacionais destacam a peculiar característica do PRONERA como um programa que tem suas ações impulsionadas pela proposição de diferentes entidades da sociedade civil organizada com o objetivo de ampliar o acesso à educação para as áreas de Reforma Agrária. Ele tem como principais parceiros os movimentos sociais e sindicais de trabalhadores rurais, o INCRA, as instituições públicas de ensino, as instituições de ensino sem fins lucrativos e os governos municipais e estaduais (BRASIL, 2004, p.18).

A execução dos projetos do PRONERA foi regulamentada a partir de uma concepção de uma gestão participativa com responsabilidades compartilhadas numa construção coletiva, abrangendo desde a elaboração dos projetos, passando pela execução, pelo acompanhamento e pela avaliação. Todos os projetos executados pelo PRONERA devem ser fundamentados segundo três pressupostos teórico-metodológicos em sua 
execução: 1 - O Princípio do Diálogo: com o objetivo de garantir o respeito à cultura dos grupos envolvidos, promover a valorização dos saberes e a produção coletiva do conhecimento; 2 - O Princípio da Práxis: com processo educativo concebido a partir da tríade ação-reflexão-ação, trata-se do entendimento freiriano da educação como função política transformadora; 3-O Princípio da Transdisciplinaridade: que destaca o caráter universal a que deve se direcionar a ação educadora, por meio da inter-relação de saberes locais, regionais e globais a partir de uma concepção ampla da educação, capaz de abranger múltiplos aspectos: sociais, culturais, políticos, econômicos, de gênero, geração e etnia.

Os princípios acima requerem práticas pedagógicas problematizadoras e participativas com o objetivo de interagir com situações concretas de vida e experiências dos educandos, a partir das quais estariam estabelecidos os eixos temáticos estruturantes dos currículos.

Porém, todas essas concepções se enfrentam com a tradição elitista e os arranjos institucionais dentro do Estado, forjados, sobretudo, a partir do Golpe de 64, que reforçou os privilégios oligárquicos do sistema político brasileiro, mesmo durante a transição para a democracia, a partir de 1984, chefiada por José Sarney, que fazia parte justamente do partido que deu sustentação à ditadura empresarial-militar por quase 20 anos. A manutenção desses setores dentro da máquina do Estado, por meio de diversa práticas, sempre prejudicou o exercício de direitos civis e políticos pela população pobre. Os obstáculos às políticas públicas redistributivas e participativas, como o PRONERA, se devem a diversas complicações institucionais, devido inclusive à fragmentação e à politização da administração pública. Como salienta Weyland (1996), essas condições têm facilitado a "infiltração" e a "tomada" de muitos órgãos públicos por determinados grupos de interesse, o que explica, por exemplo, a afinidade histórica entre o Ministério de Agricultura e as principais entidades ruralistas do país.

\section{O PRONERA: ENFRENTAMENTOS E PRINCIPAIS RESULTADOS}

Em seus 19 anos de atuação, o PRONERA contou com seis manuais normalizadores. O primeiro foi editado no ano de criação do programa, em 1998. O segundo foi publicado no ano de 2001, em função da incorporação do PRONERA ao INCRA. O terceiro data do ano de 2004, sendo marcado pela ampliação do programa. O quarto manual foi publicado em 2011, em atendimento às determinações do TCU fruto de ações judiciais contra um dos cursos ofertados pelo programa, bem como das atualizações legislativas que instituíram e regulamentaram o PRONERA como uma política pública de 
educação do campo. O quinto foi reeditado no ano de 2014, numa versão abreviada do manual de 2011. Finalmente, o manual de 2016 foi reeditado por motivações oriundas da ampliação das modalidades do curso a serem ministrados pelo PRONERA (o mestrado, por exemplo) e da interação entre o PRONERA e outros programas ofertados pelo INCRA.

Porém, o grande enfrentamento pelo qual passou o PRONERA ocorreu no ano de 2008, quando denúncias (de caráter sigiloso) foram feitas ao Tribunal de Contas da União, com respeito a possíveis irregularidades do INCRA em convênio com a Fundação de Apoio ao Ensino Superior Público Estadual (FAESP) e a Universidade Estadual do Mato Grosso (UNEMAT), para a realização do Curso Superior de Agronomia com Ênfase em Agroecologia e Sócio Economia Solidária para 60 jovens e adultos de assentamentos de Reforma Agrária dos estados de Mato Grosso, Rondônia, Minas Gerais, Goiás, Mato Grosso do Sul, Distrito Federal e Paraná, quase levando à suspensão do programa. Trata-se do Acórdão nº 2653/2008-TCU-Plenário.

Do conjunto das denúncias, uma se destaca por atingir "o coração do PRONERA", conforme apontou Félix (2015), ou seja, a participação dos movimentos sociais, pois, de acordo com o Manual de operações (2004) vigente na época, os movimentos sociais e sindicais do campo, além de indicar as necessidades de projetos, participavam do acompanhamento e da avaliação de sua execução, bem como da elaboração dos projetos educacionais. A denúncia em questão afirmava que o Projeto CAMOSC - Curso de Agronomia para os Movimentos Sociais do Campo permitia a atuação de docentes indicados pelos movimentos sociais, ferindo os princípios da impessoalidade e da moralidade presentes no Artigo 37 da Constituição Federal (BRASIL;TCU, Acórdão no 2653/2008, p.4).

Desta denúncia ficou determinado pelo TCU que o INCRA criasse normas capazes de inibir quaisquer possibilidades de que "entes estranhos à administração pública" participassem da execução, do acompanhamento, da avaliação e dos demais procedimentos do curso ofertados, em especial os movimentos sociais e sindicais ligados à Reforma Agrária (DINIZ, 2015). A determinação do TCU 2653/2008 redundou na reedição do manual de 2011, no qual restou aos movimentos sociais e sindicais do campo a exclusiva função de demandar cursos de acordo com a comprovada necessidade das áreas de Reforma Agrária.

Em que pese as consequências das decisões do TCU sobre a gestão democrática do PRONERA, o programa segue dando visibilidade não só à luta pela Reforma Agrária no país, bem como à possibilidade real de construção 
de propostas pedagógicas diferenciadas e atreladas às necessidades sociais dos educandos.

Contudo, é importante observar que o processo de intervenção judicial no campo das políticas públicas inscreve-se não apenas no caráter oligárquico da sociedade e do Estado brasileiro, mas num cenário maior marcado pela hegemonia das concepções neoliberais sobre as políticas públicas implantadas pelo Estado.

Para Mancebo (2009), o ideário que o novo capitalismo pretende atingir é uma reformulação no poder ideológico/cultural na direção de forjar uma nova concepção de "cidadão", capaz de internalizar as diferentes facetas das competências necessárias à manutenção e ao fortalecimento de uma "sociabilidade produtiva", focada nos ditames do mercado. Esses ditames do mercado podem ser traduzidos como a formação de um "ser social com uma qualidade que conjuga um ser útil, solitário e 'mudo' politicamente" (MANCEBO, 2009, p.13). É nesse contexto de conflitos e enfrentamentos que o PRONERA, juntamente com seus parceiros, foi construindo o caminho para a legitimação da educação do campo como uma proposta diferenciada e contra-hegemônica de produção do conhecimento, para a qual é útil quem é solidário e o diálogo é o expediente para a materialização de suas ações. Isso porque, diante de uma educação hegemonicamente voltada para a mercantilização da força de trabalho do homem, existe sempre a possibilidade de construção de espaços educativos voltados para a politização e a emancipação do ser social.

A proposta contida na educação do campo, como está operacionalizada nas execuções do PRONERA, pode ser vista como uma contradição dialética, na medida em que traz para o interior de um Estado Democrático de Direito uma política pública que vem buscando sintetizar a singularidade do Estado de Direito com a universalidade do Estado Democrático. O PRONERA tem um caráter contra-hegemônico e inovador, pela materialização do direito à educação para sujeitos pobres do campo que passam também a ter participação ativa, através de movimentos sociais que os representam, de sua gestão, enfrentando nos últimos anos a hegemonia em torno do chamado "consenso das commodities" (SVAMPA, 2013). A hegemonia não implica apenas uma dominação estrita do mando/ obediência, ao contrário, ela se relaciona também à aceitação oriunda de um consenso direcionado para um objetivo comum por parte das classes dominadas. Para Gramsci (2012), a disputa pela hegemonia é uma estratégia de luta política das classes subalternas a partir de sua capacidade de elaborar uma direção intelectual e moral que a tornará dirigente de um novo projeto político de sociedade (DINIZ, 2013, p.7). 
A participação popular é o que impulsionou o PRONERA, pois ele somente implementa suas ações a partir das demandas dos movimentos sociais ou de entidades sindicais que entram em contato com alguma instituição de ensino demandando a realização de uma turma de um curso específico que atenda à população das áreas de Reforma Agrária cadastradas pelo INCRA. Os cursos recebem recursos diretamente do PRONERA, efetivando-se mediante aprovação das instâncias superiores das universidades e fundações interessadas e, sobretudo, da existência de docentes da instituição que assumam a coordenação desses cursos junto com membros da organização que demandou o curso.

Segundo dados levantados no relatório da II PNERA (2015), o PRONERA realizou, no período de 1998 a 2011, um total de 320 cursos, que contaram com 82 instituições em todo o país. Esses 320 cursos estão distribuídos em: 167 de Educação de Jovens e Adultos (EJA), na modalidade fundamental; 99 cursos de nível médio, e 54 de nível superior (BRASIL; IPEA, 2015).

Para ilustrar a espacialidade da abrangência do PRONERA, consta no relatório a distribuição dos cursos por municípios, reproduzida abaixo:

Mapa 1 - Municípios [com] realização dos cursos do PRONERA por nível (1998-2011)

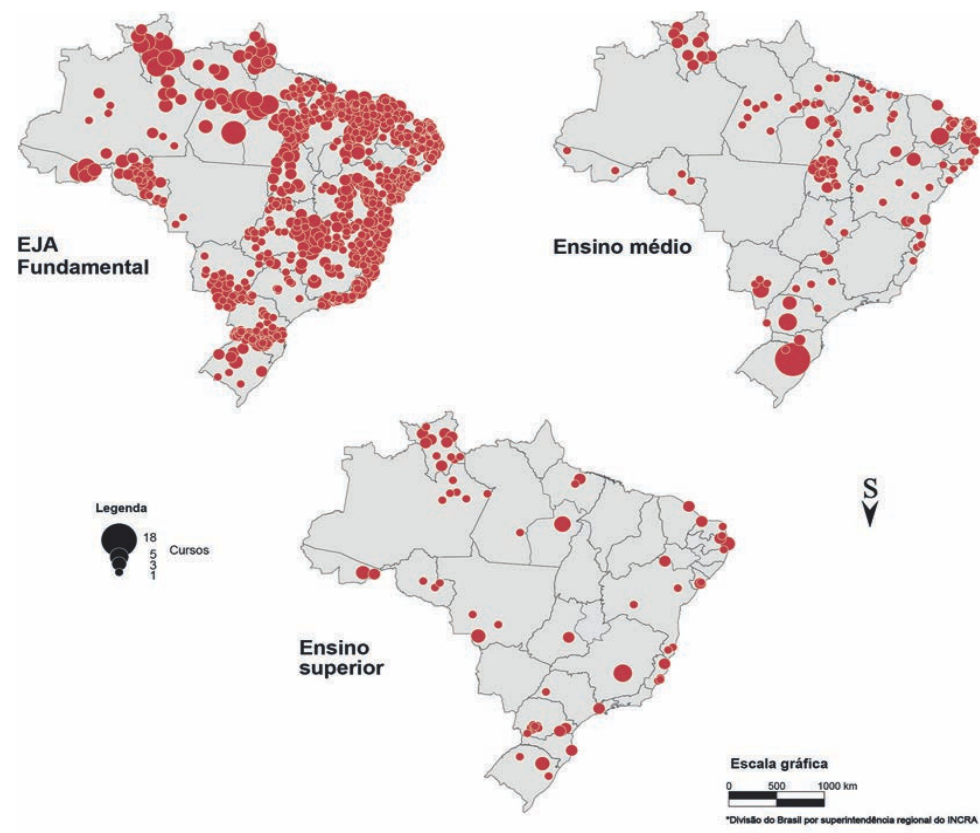

Fonte: BRASIL. IPEA. II Pesquisa Nacional de Educação na Reforma Agrária (II PNERA). Brasília, 2015. 
Pela pesquisa, é possível constatar que em quase todo o território nacional se constituíram turmas de ensino fundamental e de educação de jovens e adultos, com destaque para a região Norte do país. Já o ensino médio teve turmas concentradas no Rio Grande do Sul. E, em ensino superior, é expressivo o número de turmas graduadas em Minas Gerais, no Pará e na região Nordeste. O relatório da II PNERA também informa que 38 organizações demandaram cursos para o PRONERA, contabilizando um total de 525 demandas de atuações individuais. No que concerne à participação conjunta de organizações demandantes, 58\% advieram de movimentos sociais e sindicais, $24 \%$ de associações e $8 \%$ ficaram por conta das fundações.

Tabela 1- Organizações demandantes e números de cursos demandados individual e conjuntamente (1998-2011)

\begin{tabular}{|c|c|c|c|}
\hline Número & Organização demandante & $\begin{array}{c}\text { Número } \\
\text { de Cursos } \\
\text { Demandados }\end{array}$ & Tipologia \\
\hline 01 & $\begin{array}{c}\text { Associação de Casas Familiares Rurais do } \\
\text { Pará/Arcafar }\end{array}$ & 03 & Associação \\
\hline 02 & $\begin{array}{c}\text { Associação de Remanescentes de } \\
\text { Quilombos/PA }\end{array}$ & 02 & Associação \\
\hline 03 & $\begin{array}{c}\text { Associação de Trabalhadores Rurais de } \\
\text { Oriximiná/PA }\end{array}$ & 02 & Associação \\
\hline 04 & Associação de Trabalhadores Rurais/PA & 01 & Associação \\
\hline 05 & $\begin{array}{l}\text { Associação em Áreas de Assentamento no } \\
\text { Estado do Maranhão }\end{array}$ & 02 & Associação \\
\hline 06 & Central dos Assentamentos de Roraima & 06 & Movimento \\
\hline 07 & $\begin{array}{c}\text { Centro de Organização e Apoio aos } \\
\text { Assentados do } \\
\text { Mato Grosso do Sul }\end{array}$ & 01 & Associação \\
\hline 08 & $\begin{array}{l}\text { Comissão Pastoral da Terra/BA/GO/MS/ } \\
\text { MT/PA/PB }\end{array}$ & 31 & Pastoral \\
\hline 09 & $\begin{array}{c}\text { Confederação Nacional dos Trabalhadores } \\
\text { na Agricultura }\end{array}$ & 207 & Movimento \\
\hline 10 & $\begin{array}{c}\text { Cooperativa dos Pequenos Produtores e } \\
\text { Produtoras } \\
\text { Agroecologistas do Sul da Bahia }\end{array}$ & 03 & Cooperativa \\
\hline
\end{tabular}




\begin{tabular}{|c|c|c|c|}
\hline 11 & $\begin{array}{c}\text { Cooperativa Escola dos Alunos da Escola } \\
\text { Agrotécnica Federal } \\
\text { de Satuba/AL }\end{array}$ & 01 & Cooperativa \\
\hline 12 & $\begin{array}{l}\text { Coordenação Estadual dos Trabalhadores } \\
\text { Agrícolas/BA }\end{array}$ & 01 & Associação \\
\hline 13 & $\begin{array}{l}\text { Escola Família Agrícola de Padre Bernardo/ } \\
\qquad \mathrm{PB} / \mathrm{GO}\end{array}$ & 01 & Associação \\
\hline 14 & Escola Família Agrícola/RO & 05 & Associação \\
\hline 15 & $\begin{array}{l}\text { Federação dos Trabalhadores na } \\
\text { Agricultura Familiar/PI/PA }\end{array}$ & 04 & Movimento \\
\hline 16 & $\begin{array}{l}\text { Fundação de Apoio à Agricultura Familiar } \\
\text { do Semiárido da Bahia }\end{array}$ & 04 & Fundação \\
\hline 17 & $\begin{array}{c}\text { Fundação de Apoio aos Trabalhadores } \\
\text { Rurais e Agricultores } \\
\text { Familiares da Região do Sisal/BA }\end{array}$ & 02 & Fundação \\
\hline 18 & Fundação Viver, Produzir e Preservar/PA & 03 & Fundação \\
\hline 19 & Ligas dos Camponeses Pobres & 01 & Movimento \\
\hline 20 & Movimento das Mulheres em Marcha/PB & 01 & Movimento \\
\hline 21 & $\begin{array}{l}\text { Movimento de Libertação dos Sem Terra/ } \\
\text { PE }\end{array}$ & 02 & Movimento \\
\hline 22 & Movimento de Luta pela Terra/BA & 10 & Movimento \\
\hline 23 & Movimento de Mulheres Camponesas/MS & 02 & Movimento \\
\hline 24 & $\begin{array}{l}\text { Movimento de Mulheres do Campo e da } \\
\text { Cidade }\end{array}$ & 01 & Movimento \\
\hline 25 & $\begin{array}{c}\text { Movimento de Mulheres Trabalhadoras de } \\
\text { Altamira do Campo e } \\
\text { da Cidade/PA }\end{array}$ & 01 & Movimento \\
\hline 26 & $\begin{array}{c}\text { Movimento Estadual de Trabalhadores } \\
\text { Assentados Acampados e } \\
\text { Quilombolas/BA }\end{array}$ & 08 & Movimento \\
\hline 27 & $\begin{array}{l}\text { Movimento dos Atingidos por Barragem/ } \\
\text { GO }\end{array}$ & 01 & Movimento \\
\hline 28 & $\begin{array}{l}\text { Movimento dos Pequenos Agricultores/ } \\
\qquad \mathrm{AC} / \mathrm{MT} / \mathrm{PB} / \mathrm{RO}\end{array}$ & 07 & Movimento \\
\hline 29 & $\begin{array}{l}\text { Movimento dos Trabalhadores } \\
\text { Desempregados/BA/PB }\end{array}$ & 03 & Movimento \\
\hline
\end{tabular}




\begin{tabular}{|c|c|c|c|}
\hline 30 & $\begin{array}{c}\text { Movimento dos Trabalhadores Rurais e } \\
\text { Urbano do Brasil/PE }\end{array}$ & 01 & Movimento \\
\hline 31 & $\begin{array}{c}\text { Movimento dos Trabalhadores Rurais Sem } \\
\text { Terra }\end{array}$ & 190 & Movimento \\
\hline 32 & $\begin{array}{c}\text { Movimento Pelo Desenvolvimento da } \\
\text { Transamazônica e } \\
\text { Xingu/PA }\end{array}$ & 01 & Movimento \\
\hline 33 & $\begin{array}{l}\text { Movimento Popular pela Reforma Agrária/ } \\
\text { MG }\end{array}$ & 02 & Movimento \\
\hline 34 & Movimento Terra Livre & 01 & Movimento \\
\hline 35 & Movimento Terra Trabalho e Liberdade & 04 & Movimento \\
\hline 36 & $\begin{array}{c}\text { Organização de Mulheres Assentadas e } \\
\text { Quilombolas do } \\
\text { Estado de São Paulo }\end{array}$ & 02 & Movimento \\
\hline 37 & $\begin{array}{l}\text { Pastoral da Juventude Rural/BA/GO/MT/ } \\
\text { PB/RO }\end{array}$ & 05 & Pastoral \\
\hline \multirow[t]{2}{*}{38} & Pólo de Unidade Camponesa/BA & 03 & Movimento \\
\hline & Demandas Conjuntas/Brasil & 525 & \\
\hline
\end{tabular}

Fonte: BRASIL. IPEA. II Pesquisa Nacional de Educação na Reforma Agrária (II PNERA). Brasília, 2015.

Como vemos, em que pese a expressiva demanda de cursos por parte da Confederação Nacional dos Trabalhadores na Agricultura (CONTAG) e do MST, há 36 movimentos sociais que demandam cursos e se inserem em uma política pública de caráter educacional, o que, num país com histórica defasagem educacional das populações do campo, implica em si um mudança significativa. A participação direta numa política pública evidencia a necessidade de mudança e representa para esses atores uma maneira nova de atuar no cenário social e político, abrindo caminho para o debate e a negociação dos rumos de um determinado grupo social historicamente marginalizado de políticas educacionais específicas

É interessante observar que a participação, base do funcionamento do PRONERA, está vinculada à luta pela terra e pela Reforma Agrária, desafios históricos ainda em pauta no cenário político brasileiro. Para Martins (1983), os camponeses passaram a ser um grupo social sem lugar na estrutura social e política nascente com a República. Um estranho que nenhum grupo político e de classe irá reconhecer como cidadão, ou mesmo como aliado real ou potencial. A esse grupo pertence o sem-terra, o sem-trabalho, um excluído do 
pacto político, no dizer de Martins (MARTINS, 1983, p.25). A Lei de Terras de 1850, ao desvincular a posse da terra do direito de propriedade, tornando-a uma mercadoria livre de regulações de seu uso, criou novas modalidades de desigualdades. O camponês passa a figurar neste novo complexo de desigualdade, na medida em que fica dependente dos fazendeiros para gerir seus meios de vida. Tornava-se, então, agregado, tendo seus direitos estritamente vinculados à concessão do fazendeiro, tratando-se, como explicitou Martins (1983), de uma questão privada e não pública. Nela, havia uma relação baseada "[...] na troca de serviços e produtos por favores, troca direta de coisas desiguais, controlada através de um complicado balanço de favores prestados e favores recebidos" (MARTINS, 1983, p. 35).

É deste contexto histórico que vai se desenhando ao longo dos anos a luta dos movimentos sociais pela Reforma Agrária, até chegar à organização pelo direito à educação. Stédile (1999), em entrevista concedida a Bernardo Mançano, explica o significado da educação para o MST, hoje acompanhado por diversos movimentos sociais do campo. Para ele, na guerra é necessário estar em várias frentes e uma delas é enfrentar a "cerca da ignorância". Segundo ele, "a batalha da educação é tão importante quanto a da ocupação de um latifúndio. A nossa luta é para derrubar três cercas: a do latifúndio, a da ignorância e a do capital" (FERNANDES; STÉDILE, 1999, p. 74). É deste processo de luta pela Reforma Agrária que nasce e se desenvolve o Programa Nacional de Educação na Reforma Agrária (PRONERA).

\section{CONSIDERAÇÕES FINAIS}

Considera-se que o PRONERA consiste numa política pública inserida no rol da "grande política", Admite-se que, onde o Estado se coloca como aquele capaz de determinar quais e a quem distribuir poder e direitos, não há democracia. Onde a sociedade civil, representada principalmente pelas classes subalternas, é colocada na condição de mera observadora das ações do Estado, não há democracia.

A grande política está presente na proposta das ações do PRONERA por representar uma nova inserção na institucionalidade estatal. Expressa, sobretudo, na execução de um projeto educacional contra-hegemônico, simplesmente por atender o público de assentados de Reforma Agrária e agricultores familiares, conceitos que hoje definem o campesinato brasileiro que sempre esteve fora das políticas públicas construídas para o meio rural, hegemonicamente indutoras do agronegócio, ou seja, da agricultura capitalista baseada na monocultura e na produção de commodities para a exportação, geralmente intensiva em tecnologia e com fraca demanda de 
mão de obra. A educação do campo está inserida no projeto da indução da agricultura camponesa, caracterizada pela policultura, pelo uso dos múltiplos recursos naturais, pelo atendimento tanto do mercado interno como do externo, visando à democratização das riquezas naturais do país e ao desenvolvimento local. Ela parte de uma concepção do campo holística e não apenas como território exclusivo do negócio (FERNANDES; MOLINA, 2004).

Pelo seu modus operandi fundamentado na gestão participativa, o PRONERA também é uma alternativa contra a ordem discursiva do neoliberalismo de desapropriação e despolitização da política. Porque, segundo as afirmações de Giroux (2015), o neoliberalismo se mantém pela ordem discursiva da:

Desapropriação e despolitização [por meio de uma] linguagem que molda identidades, desejos, valores e relações sociais. Como observou Dormem Mace, sob o neoliberalismo o público é convidado a se tornar consumidor, [porque] os únicos interesses que importam são os interesses individuais, quase sempre medidos por considerações monetaristas. Sob tais circunstâncias, obrigações sociais e comunais foram trituradas, modos importantes de manifestação de solidariedade, atacados, e uma guerra é travada contra qualquer instituição que abrange valores, práticas e relações sociais peculiares à democracia (GIROUX, 2015, p.3, tradução nossa).

Dentro desta perspectiva, o PRONERA deve submeter-se a uma reavaliação constante de seus princípios constitutivos, a partir do que Maquiavel entendeu como fundação contínua, que é o que garante a "saúde" de qualquer instituição social.

A concepção maquiaveliana de fundação contínua remete à manutenção de uma determinada ordem política, ou seja, a luta pela conservação de uma determinada ordem política implica conservar no tempo a força motivada do "primeiro gesto" (BIGNOTTO, 1991, p.135).

O grande objetivo de Maquiavel, em O príncipe, é a ação do príncipe novo na conquista e na instauração da nova ordem política. Neste sentido, o príncipe de Maquiavel consiste num universal abstrato que representa qualquer ator político que objetiva uma nova instituição do político como alternativa à ordem existente. Para Maquiavel, a eficácia de uma nova instituição política advém da explicitação dos conflitos sociais e se conserva desde que a dimensão inovadora que impulsionou sua criação se mantenha viva, mesmo diante das contingências ou mudanças postas pelo movimento inevitável da história. E isso não se faz pela força, mas pelo consenso constantemente renovado da dimensão popular, uma vez que toda ação política é o conflito entre dois desejos, aquele que dirige pelo 
poder que possui e aquele que é dirigido pelo poder do seu consentimento permanentemente reposto pela fundação contínua. A fundação é contínua na medida em que toda ação criadora encontra-se imersa na indeterminação do mundo histórico (BIGNOTTO, 1991).

A fundação contínua - explicita Bignotto - é necessária exatamente porque toda forma política corre o risco de se degenerar, a tal ponto que a ação humana perde sua força criadora, ou seja, de tal modo que a refundação não seja mais possível (BIGNOTTO, 1991, p.166).

A força criadora do Programa Nacional de Educação na Reforma Agrária é o seu caráter participativo e o fato de ser produto da luta social pela terra e pela Reforma Agrária. Sua fundação contínua é renovar esse caráter, apesar das inevitáveis transformações históricas. Recuar do princípio fundador é também degenerar-se como uma política pública comprometida com a grande política.

E, finalmente, o PRONERA tem que exigir de seus parceiros a colaboração necessária para manter a força do "primeiro gesto" de seus princípios constitutivos para não perder seu status de um programa de Estado em luta pela grande política. Suas características que contribuem para a retomada da força do "primeiro gesto" são a gestão participativa e compartilhada, reforçando, nas entidades em luta pela Reforma Agrária, a consciência de que deram vida à educação do campo e ao PRONERA.

Entendemos que o PRONERA, pela sua própria estrutura administrativa, contém mecanismos importantes capazes de prosseguir contribuindo para a democratização do Estado Democrático de Direito no Brasil. Neste sentido é que o programa se inscreve no universo das possibilidades que somente afloram mediante as contradições da historicidade dialética do mundo, capaz de romper a quietude determinista e dogmática que exime os seres humanos da responsabilidade de serem autores de sua própria história.

Artigo recebido em: 27/03/2017

Aprovado para publicação em: 16/05/2017

THE NATIONAL PROGRAM FOR EDUCATION IN AGRARIAN REFORM (PRONERA): A PUBLIC POLICY FOR THE DEMOCRATIZATION OF THE STATE IN BRAZIL

ABSTRACT: The National Program of Education in theAgrarian Reform (PRONERA in Portuguese)is a public policy of the federal Government of Brazil, which aims to promote educational activities in the regions of agrarian reform from courses geared to the reality of rural areas through a participatory and shared management. This 
article aims to give lecture on the trajectory of the National Program of Education in the Agrarian Reform (PRONERA) showing how your operation contributes to the democratization of the State of Brazil by the participatory character, your foundational feature of the program that must be constantly updated.

KeYwords: Public policy. Participation. Social movements. Education field.

EL PROGRAMA NACIONAL DE EDUCACIÓN EN LA REFORMA AGRARIA (PRONERA): UNA POLÍTICA PÚBLICA PARA DEMOCRATIZACIÓN DEL ESTADO EN BRASIL

Resumen: El Programa Nacional de Educación en la Reforma AgrariaPRONERA es la política pública del gobierno federal que tiene como objetivo promover actividades educativas en las regiones de la reforma agraria de cursos adaptado a la realidad de las zonas rurales a través de una gestión participativa y compartida. Este artículo pretende dar Conferencia sobre la trayectoria del programa nacional de educación sobre la reforma agraria (PRONERA) mostrando cómo su operación contribuye a la democratización del estado en Brasil por el carácter participativo, su característica fundamental del programa que debe ser constantementeactualizada.

Palabras Clave: Políticas públicas. Participación.Movimientos sociales. El campo de la educación.

\section{NOTAS}

1 Houve pelo menos dois processos conhecidos que tentaram impedir a criação ou a formatura de turmas de cursos de graduação apoiados pelo PRONERA. Um no Rio Grande do Sul, que retardou a criação da turma de Veterinária na Universidade Federal de Pelotas, e o outro em Goiás, que ameaçava impedir a formatura da primeira turma de Direito criada com apoio do PRONERA. Ambos os processos ameaçaram as turmas formadas, mas foram derrotados. O específico deste processo que será citado neste artigo é que ele desencadeou uma mudança dentro da política como um todo, mas este não é o objeto central de reflexão deste artigo.

2 Decreto no 1946, de 28 de junho de 1996. Antes do PRONAF, o governo Itamar Franco criou o Programa de Valorização da Pequena Produção (PROVAP), atendendo às demandas dos movimentos sociais do campo (MST, Confederação Nacional de Trabalhadores na Agricultura (CONTAG), Departamento Nacional de Trabalhadores Rurais da CUT (DNTR/CUT)), Movimento de Mulheres Agricultoras, Movimento dos Atingidos por Barragens, Conselho Nacional de Seringueiros, Movimento Nacional dos Pescadores) que se mobilizaram conjuntamente no "Grito da Terra", ocorrido nos dias 9 e 13 de maio de 1994. Em 1995, houve o II Grito da Terra, reunindo novamente 
diversos movimentos sociais do campo que exigiram, entre outras pautas, crédito diferenciado para a pequena produção familiar

3 "A grande política compreende as questões políticas ligadas à fundação de novos Estados, à luta pela destruição, pela defesa, pela conservação de determinadas estruturas orgânicas econômico-sociais. A pequena política compreende as questões parciais e cotidianas que se apresentam no interior de uma estrutura já estabelecida em decorrência de lutas pela predominância entre diversas frações de uma mesma classe política" (GRAMSCl, 2012, p.21-22). Gramsci completa afirmando que também é grande política a exclusão da grande política das ações estatais, reduzindo tudo à pequena política, fato recorrente nos tempos atuais.

\section{REFERÊNCIAS}

ALMEIDA, R. A. de. Gestão democrática na formatação de políticas. 2014. 257 f. Tese (Doutorado) - Universidade Federal do Rio de Janeiro, Instituto de Economia, Programa de Pós-Graduação em Políticas Públicas, Estratégias e Desenvolvimento, Rio de Janeiro, 2014.

BIGNOTTO, N. Maquiavel republicano. São Paulo: Ed. Loyola, 1991

BOBBIO, N.; MATEUCCI, N.; PASQUINO, G. Dicionário de política. Brasília: UnB, 1992. v.I. BRASIL. Constituição da República Federativa do Brasil. Brasília, 2010. Disponível em: <http://www.senado.gov.br/legislacao/const/con1988/CON1988_05.10.1988/ CON1988.pdf>. Acesso em: 29 dez. 2015.

BRASIL. Ministério do Desenvolvimento Agrário. INCRA; PRONERA. Manual de operações. Brasília, 1998.

BRASIL. IPEA. II Pesquisa Nacional de Educação na Reforma Agrária (II PNERA). Brasília, 2015.

BRASIL. Ministério do Desenvolvimento Agrário. INCRA; PRONERA. Manual de operações. Brasília: MDA, 2016.

BRASIL. Ministério do Desenvolvimento Agrário. INCRA; PRONERA. Manual de operações. Brasília: MDA, 2012.

BRASIL. Ministério do Desenvolvimento Agrário. INCRA; PRONERA. Manual de operações. Brasília: MDA, 2014.

BRASIL. Ministério do Desenvolvimento Agrário. INCRA; PRONERA. Manual de operações. Brasília: MDA, 2004.

BRASIL. Ministério Público Federal; Procuradoria da República do Estado de Goiás. Procedimento administrativo MPF 1.18.000.023126/2007-47. Brasília, DF, 2007.

BRASIL. Tribunal de Contas da União. Acórdão n. 2356, 2010, 2010.

BRASIL. Tribunal de Contas da União. Acórdão n. 2653/2008 - Plenário, 2008. 
CANCLINI, N. G. Consumidores e cidadãos: conflitos multiculturais da globalização. Rio de Janeiro: Ed. UFRJ, 1999.

CARTER, M. Broken promise: the land reform debacler under de PT governements. In: Challenging social inequality: the Landless Rural Workers Movement and Agrarian Reform in Brazil. Durham: Duke University Presse, 2015.

CHAUI, M. Raízes teológicas do populismo no Brasil: teocracia dos dominantes, messianismo dos dominados. In: DAGNINO, Evelina (Org.). Anos 90: política e sociedade no Brasil. São Paulo: Brasiliense, 1994.

DELGADO, G. C. A questão agrária e o Agronegócio no Brasil. In: CARTER, Miguel. Combatendo a desigualdade social: o MST e a Reforma Agrária no Brasil. São Paulo: Editora UNESP, 2010. p. 81-112

DINIZ, D. F. MST e a construção de uma subjetividade contra-hegemônica: uma proposta analítica dos princípios filosóficos da educação do MST. 2013. Disponível em: <www.diagramaeditorial.com.br/universitas/.../eixo7/daise_diniz.doc >. Acesso em: 30 de jun. 2013.

. O Programa Nacional de Educação na Reforma Agrária (PRONERA). Gestão participativa e ativismo judicial. Revista Plurimus Cultura e Desenvolvimento em Revista, ano IV, ed. VIII. jul./dez. 2015. Disponível em: <www.plurimus.com.br>. Acesso em: 11 dez. 2015.

FELIX, N. Programa Nacional de Educação na Reforma Agrária (PRONERA): história, estrutura, funcionamento e características. [S.I: sn], 2015.

FERNANDES, B. M.; STÉDILE, J. P. Brava gente: a trajetória do MST e a luta pela terra no Brasil. São Paulo: Editora Perseu Abramo, 1999.

; MOLINA, M. C. O campo da educação do campo. In: Articulação nacional por uma educação básica do campo. Brasília, 2004. (Coleção Por uma Educação do Campo, v.5).

FREIRE, R. de B. Participação política como exercício de cidadania. 2006. 176 f. Tese (Doutorado) - Universidade de São Paulo, 2006.

GIROUX, H. D. Trump and the ghosts of totalitarianism. Disponível em: <http://www. counterpunch.org/2015/09/18/donald-trump-and-the-ghosts-of-totalitarianism>. Acesso em: 26 de set. 2015.

GRAMSCl, A. Cadernos do cárcere. Rio de Janeiro: Civilização Brasileira, 2012. v. 3.

MARTINS, J. S. Os camponeses e a política no Brasil: as lutas sociais no campo e seu lugar no processo político. Petrópolis, RJ: Vozes, 1983.

MANCEBO, D. et al. Políticas de expansão da educação superior no Brasil pós-LDB (Projeto do Observatório de Educação Superior- Obeduc/UERJ- Rede Universitas/ Br), 2009, Disponível em: <www.obeduc.uerj.br/arquivos/livpolpub3.pdf>. Acesso em: 20 ago. 2015. 
MOLINA, M. A contribuição do PRONERA na construção de políticas públicas de educação do campo e desenvolvimento sustentável. 2003. 150 f. Tese (Doutorado) - Centro de Desenvolvimento Sustentável, 2003.

MONTERO, A. Brazilian politics. Cambridge: Polity,2005.

RODRIGUES, M. M. A. Políticas públicas. São Paulo: Publifolha, 2010.

SVAMPA, M. «Consenso de los commodities» y lenguajes de valoración en América Latina. Revista Nova Sociedad, n.244, p. 30-46, mar./abril 2013.

WEYLAND, K. Democracy without equity: failures of reform in Brazil. Pittsburgh: Pittsburgh University Press,1996.

DAISE FerReIRA DINIZ: Bacharel e licenciada em Filosofia pela Universidade Federal de Minas Gerais, especialista em Ciência Política pela Universidade Federal de Minas Gerais, mestre em Ciência Política pela Universidade Federal de Minas Gerais e doutora em Políticas Públicas e Formação Humana pela Universidade do Estado do Rio de Janeiro. Pesquisadora da Rede Universitas/BR. coordenado pela Profa. Dra Deise Mancebo. Atua nas áreas de Filosofia Política, Ciência Política, Políticas Públicas, Educação do Campo, Movimentos Sociais, Democracia e Política Brasileira.

E-mail: daisef.diniz@gmail.com

Débora Franco Lerrer: Professora-adjunta do Programa de Pós-Graduação de Ciências Sociais em Desenvolvimento, Agricultura e Sociedade da UFRRJ. Fez pós-doutorado no Programa de Pós-Graduação em Políticas Públicas e Formação Humana da UERJ. Fez doutorado no CPDA e mestrado em Ciências da Comunicação pela Universidade de São Paulo (1998). É jornalista e tem dois livros publicados sobre questão agrária. Desenvolve pesquisas em torno dos seguintes temas: Movimento dos Trabalhadores Rurais Sem Terra, questão agrária, agronegócio, mediações jornalísticas e educação superior no campo.

E-mail: debora.lerrer.cpda@smail.com 